\title{
Ярослав Сандрачук
}

аспирант, ДЗВО «Університет менеджменту освіти»,

2. Киев, Украина, e-mail: yasand@ukr.net

https://orcid.org/0000-0002-2205-7038

\section{ОТДЕЛЬНЫЕ ПРОБЛЕМЫ РАССМОТРЕНИЯ АДМИНИСТРАТИВНЫМИ СУДАМИ УКРАИНЫ СПОРОВ, ВОЗНИКАЮЩИХ В СФЕРЕ РЕАЛИЗАЦИИ ПРАВА НА ПУБЛИЧНУЮ СЛУЖБУ}

Аннотация. Статья посвящена исследованию некоторых проблемных вопросов, возникающих при рассмотрении споров, проистекающих из сферы реализации гражданами Украины права на публичную службу. Определено содержание права на реализацию публичной службы; произведён анализ судебной практики рассмотрения дел данной категории.

Выявлены и охарактеризованы особенности рассмотрения административными судами Украины дел, возникающих из споров, связанных с принятием на публичную службу, прохождением такой службы. Установлено, что в украинском законодательстве предусмотрен обязательный досудебный порядок урегулирования споров, возникающих в связи с реализацией права на публичную службу. Однако, поиск судебной практики отказа в доступе к правосудию в связи с несоблюдением досудебного порядка обжалования решений, действий или бездействия по делам, связанным с защитой права на публичную службу, показал, что указанное положение Закона является декларативным.

Определено, что наиболее частыми причинами обращения в суд с исками по делам о принятии на государственную службу являются: нарушение порядка автоматизированной обработки результатов тестового задания, которое должно осуществляться сразу после окончания времени, отведенного на составление тестирования; неправомочный состав конкурсной комиссии или назначение конкурса лицом, которое не имеет законных полномочий в этой сфере и др.

На основании произведённого научного анализа сделан вывод о подведомственности административным судам категорий споров, возникающих по поводу принятия граждан на публичную службу и ее прохождения; выявлены проблемные аспекты судебного рассмотрения такой категории дел и выдвинуты предложения об устранении выявленных проблемных вопросов. 
Ключевые слова: публичная служба, административные суды, проблемные вопросы.

\title{
Yaroslav Sandrachuk
}

Postgraduate student of the State Institution of

Higher Education University of Educational

Management National Academy of Educational Sciences of Ukraine

Kyiv, Ukraine, e-mail: yasand@ukr.net

https://orcid.org/0000-0002-2205-7038

\section{THE CERTAIN PROBLEMS OF CONSIDERATION BY THE ADMINISTRATIVE COURTS OF UKRAINE OF DISPUTES ARISING IN THE SPHERE OF EXERCISING THE RIGHT TO PUBLIC SERVICE}

\begin{abstract}
The article is devoted to the study of some problematic issues arising in the consideration of disputes arising from the implementation of the right to public service by citizens of Ukraine. The content of the right to implement public service has been determined; the analysis of the judicial practice of considering cases of this category is made.

The article reveals and characterizes the peculiarities of consideration by the administrative courts of Ukraine of cases arising from disputes related to admission to public service, the passage of such service. It was established that the Ukrainian legislation provides for a mandatory pre-trial procedure for resolving disputes arising in connection with the exercise of the right to public service. However, the search for judicial practice of denying access to justice in connection with non-compliance with the pre-trial procedure for appealing decisions, actions or inaction in cases related to the protection of the right to public service showed that this provision of the Law is declarative.

It has been determined that the most common reasons for filing claims in court in cases of admission to the civil service are: violation of the procedure for automated processing of the test task results, which should be carried out immediately after the end of the time allotted for the preparation of testing; unauthorized composition of the competition commission or appointment of the competition by a person who does not have legal authority in this area, etc.

On the basis of the scientific analysis, it was concluded that the categories of disputes arising from the admission of citizens to public service and its passage were subordinate to the administrative courts; the problematic aspects of judicial consideration of this category of cases were identified and proposals were made to eliminate the identified problematic issues.
\end{abstract}

Keywords: public service, administrative courts, problematic issues. 
Постановка проблемы. После принятия Закона Украины «О государственной службе» в Украине изменились правила защиты права граждан на государственную службу, в частности, в судебном порядке. При этом актуальным вопросом является научное обоснование особенностей рассмотрения дел, возникающий из споров, связанных с прохождением публичной службы.

Анализ последних исследований и публикаций. Проблематикой вопросов, возникающих при рассмотрении споров, проистекающих из сферы реализации гражданами Украины права на публичную службу занимались такие отечественные ученые: Акулов-Муратов В., Банчук О., Дишлева И., Костюк В., Цуркан М.

Цель статьи: определить проблемные моменты судебного рассмотрения категорий споров, возникающих по поводу принятия граждан на публичную службу, ее прохождения и найти способы устранения проблемных вопросов.

Изложение основного материала. Самостоятельной категорией дел, относящихся к юрисдикции административных судов, являются дела, касающиеся разрешения споров о принятии граждан на публичную службу, ее прохождение и увольнение. При рассмотрении таких дел судами административной юстиции осуществляется защита прав граждан в сфере прохождения публичной службы, которое гарантировано Конституцией Украины, Законом Украины «О государственной службе» и др. В частности, согласно ч. 2 ст. 38 Конституции Украины граждане пользуются равным правом доступа к государственной службе, а также к службе в органах местного самоуправления. В связи с этим судебная защита права на публичную службу имеет важное значение в контексте реализации гарантий в сфере государственного управления, а поэтому является актуальным направлением исследования в современной науке государственного управления.

\section{защиты \\ Содержание права на публичную службу как предмета судебной}

Исследуя вопрос судебной защиты права на публичную службу, необходимо выяснить содержание права на реализацию публичной службы, защита которого относится к юрисдикции административных судов.

Как отмечают некоторые ученые, основными особенностями права на публичную службу являются следующие: это системное, конституционное право; проистекает из содержания права на труд; системно связано с правом на государственную службу и службу в органах местного самоуправления; правомочными лицами являются граждане Украины; предусматривает занятия лицом должностей в публично-правовых институтах власти; предусматривает специальную процедуру реализации, обеспечения и правовой охраны; обусловливает возникновение, изменение, прекращение служебно-трудовых правоотношений [5].

Определяя право на публичную службу, важно установить момент 
приобретения такого права и его прекращения.

По этому поводу следует согласиться с И. Дышлевой, которая, учитывая украинское законодательство, отмечает, что в нашей стране государственная служба выступает важным институтом непосредственного участия граждан в управлении государственными делами. Возникновение статуса государственного служащего определяется моментом возникновения административной правосубъектности, которая наступает с даты замещения (занятия) им определенной государственной должности [3].

Вместе с тем, необходимо учитывать, что защита права на публичную службу может возникнуть у лица ранее, чем такое лицо приобретет правовой статус государственного служащего или служащего другой публичной службы. Такая ситуация может возникнуть в случае, если лицо, к примеру, обжалует решение конкурсной комиссии, которым было признано победителем конкурса другое лицо. Кроме того, после прекращения пребывания лица на публичной службе, последнее может обратиться в суд с целью защиты своего права на пенсионное или другое социальное обеспечение. Хотя такие споры можно отнести к отдельной категории споров в сфере пенсионного и социального обеспечения лиц, которые были освобождены от должностей публичной службы; такие споры требуют отдельного научного исследования.

Считаем, что право на публичную службу в контексте его судебной защиты, целесообразно рассматривать в широком смысле, не ограничиваясь при этом правами, которые реализуются непосредственно служащими. В таком случае содержание права на публичную службу включает:

1) право свободного доступа к публичной службе лиц независимо от их расы, социального или материального положения и т.п.;

2) права, которые реализуются должностным лицом, находящимся на должности публичной службы, в частности: право на карьерный рост; право на повышение квалификации; и т.п.;

3) права, связанные с увольнением и восстановлением в должности неправомерно уволенных служащих.

В административные суды могут быть обжалованы решения, действия и/или бездействие органов и должностных лиц, нарушающих приведенные выше права человека в сфере назначения, прохождения и увольнения с публичной службы.

По этому поводу необходимо согласиться с мнением М. И. Цуркана о том, что первичным диспозитивным правом является право на обращение в административный суд за защитой, то есть право инициировать административный процесс. Это право следует отличать от права на судебную защиту, поскольку право на обращение в суд может реализовать лицо, являющееся процессуально дееспособным, а право на судебную защиту имеет каждый, чьи права, свободы или интересы нарушены [26].

Особенности рассмотрения дел, возникающих из споров, связанных с принятием на публичную службу 
Характерно, что статьей 11 Закона Украины «О государственной службе» фактически установлено обязательное досудебное разрешение споров, возникающих в связи с защитой права на государственную службу. В частности, этой статьей предусмотрено, что в случае нарушения предоставленных настоящим Законом прав или возникновения препятствий в реализации таких прав государственный служащий в месячный срок со дня, когда он узнал или должен был узнать об этом, может подать руководителю государственной службы жалобу с указанием фактов нарушения его прав или препятствий в их реализации. В жалобе государственный служащий может требовать от руководителя государственной службы создания комиссии для проверки изложенных в жалобе фактов.

Отмечается, что руководитель государственной службы обязан не позднее 20 календарных дней со дня получения жалобы предоставить государственному служащему обоснованный письменный ответ (решение). В случае неполучения в установленный частью третьей настоящей статьи срок обоснованного ответа на жалобу или несогласия с ответом руководителя государственной службы государственный служащий может обратиться с соответствующей жалобой в суд [25].

Таким образом, из анализа приведенной правовой нормы следует, что с жалобой в суд лицо может обратиться только в случае неполучения в установленный срок обоснованного ответа или несогласия с таким ответом руководителя государственной службы, поэтому, судебной защите должно предшествовать обязательное обращение к руководителю государственной службы.

Соответствующие изменения в ст. 11 Закона Украины «О государственной службе» были внесены Законом Украины «О внесении изменений в некоторые законы Украины относительно перезагрузки власти» от 19.09.2019 № 117-IX [24].

Это в полной мере согласуется с новой конституционной концепцией, определенной в ст. 124 Конституции Украины (1996), о том, что Законом может быть определен обязательный досудебный порядок урегулирования спора. Напомним, что соответствующие изменения были внесены в Конституцию Украины Законом Украины № 1401-VIII от 02.06.2016.

До внесения указанных изменений ст. 11 Закона Украины «О государственной службе» предусматривала две альтернативные формы защиты права на государственную службу - в административном (внесудебном) и судебном порядке.

Однако, поиск судебной практики отказа в доступе к правосудию в связи с несоблюдением досудебного порядка обжалования решений, действий или бездействия по делам, связанным с защитой права на публичную службу, показал отсутствие таких случаев. То есть указанное положение Закона пока остается декларативным.

Исследуя вопрос рассмотрения административными судами споров, 
возникающих в сфере реализации каждой из трех выше выделенных групп прав на публичную службу, необходимо учитывать особенности порядка рассмотрения соответствующей категории дел и проблемные аспекты, с которыми сталкиваются суды во время такого рассмотрения.

Так, что касается судебной защиты права на свободный и равный доступ к публичной службе, то наиболее распространенными в этой сфере являются споры, возникающие по жалобам на решения конкурсной комиссии, других субъектов, уполномоченных принимать решения в сфере конкурсного отбора, об отмене результатов конкурсного отбора и др.

В обоснование неправомерности обжалуемого решения, как правило, приводят следующие аргументы: 1) нарушение порядка автоматизированной обработки результатов тестового задания, которая должна осуществляться сразу после окончания времени, отведенного на составление тестирования (Верховный Суд, 2018); 2) неправомочный состав конкурсной комиссии или назначение конкурса лицом, которое не имеет законных полномочий в этой сфере (Верховный Суд, 2019); 3) неправомерность допуска участника к проведению экзамена, в частности, по основаниям несоответствия такого участника квалификационным или иным требованиям, установленным законодательством к соответствующей категории служащих (Верховный Суд, 2019); 4) не привлечение экспертов по вопросам управления персоналом во время тестирования, как того требуют положения законодательства (Верховный Суд, 2019) и т.д.

Некоторые ученые на основании проведенного анализа судебной практики по рассмотрению дел этой категории, констатируют, что административные суды выявили следующие основные недостатки конкурсного отбора: несвоевременное проведение специальной проверки подразделениями внутренней безопасности кандидатов на должности публичного служащего, незавершение такой проверки к моменту принятия решений конкурсными комиссиями; отказ руководителей территориальных органов выполнять решение конкурсных комиссий о рекомендации/не рекомендация кандидата к прохождению службы и др. [2].

При этом следует отметить, что особенностью рассмотренной вышеприведённой категории дел является то, что лицо - жалобщик может и не иметь статуса публичного служащего, но быть кандидатом на соответствующую должность. Решая спор в указанной категории дел, административные суды выясняют: нарушены права или интересы лица, обратившегося в суд, то есть является ли такое лицо участником конкурса или лицом, которое не допущено к участию в конкурсе; полномочным ли является состав конкурсной комиссии; соблюдены ли порядок и сроки объявления конкурса; правомерно ли допущено/не допущено лицо к участию в конкурсе, что предполагает не только проверку факта соответствия/несоответствия кандидата предъявляемым квалификационным и другим требованиям, но и факта правомерности выдвижения таких требований (то есть предусмотрены 
ли соответствующие требования законодательством); соблюдены ли все этапы процедуры конкурсного отбора; объективно ли проведена оценка результатов конкурса; правильно ли определены результаты конкурса или отдельного его этапа.

Определенные особенности имеют дела, возникающие из споров, связанных с назначением на должность судьи, прокурора и некоторые другие должности, в которых решение по этому поводу принимают Верховная Рада Украины, Президент Украины, Высший совет правосудия, Высшая квалификационная комиссия судей Украины, Квалификационнодисциплинарная комиссия прокуроров.

Прежде всего следует отметить, что Кодекс административного судопроизводства Украины [4] определяет, что судом первой инстанции по таким делам является Верховный Суд, а судом апелляционной инстанции Большая Палата Верховного Суда. Судебное решение Верховного Суда по таким делам вступает в законную силу по истечении срока подачи апелляционной жалобы, если такую жалобу не было подано.

Например, в делах по искам участников конкурсного отбора на должность судьи или лиц, допущенных к такому конкурсу, в Высшую квалификационную комиссию судей, как правило, обжалуются решения комиссии по: не допуску лица к участию в конкурсе (Большая Палата Верховного Суда, 2018, 2019); нарушение разумного срока принятия решения о предоставлении рекомендаций комиссией по назначению на должность судьи (Большая Палата Верховного Суда, 2019) и т.д.

Многочисленными также являются споры по аналогичным искам к Квалификационно-дисциплинарной комиссии прокуроров (Большая Палата Верховного Суда, 2019).

Особенности рассмотрение дел, возникающих из споров, связанных с прохождением публичной службы

Следующую условную группу судебных дел в сфере реализации права на публичную службу составляют дела по спорам, возникающим непосредственно по поводу прохождения службы, то есть те, в которых истцом выступает публичный служащий.

По этому поводу интересное мнение высказано В. Акулов-Муратовым, который отметил, что сейчас в Украине не используется антропоцентрический подход к процессам управления, особенно на государственной службе. Это, как считает ученый, мешает воплощению одного из главных правил public administration: если исполнитель не справился с задачей - виноват руководитель, который по своему статусу должен использовать все возможности влияния на подчиненного, оценивая его способности заранее, а также вовремя разъясняя исполнителю задачи и контролируя их выполнение. Однако, если государственный служащий обращается в административный суд в Украине, то это, скорее всего, будет свидетельствовать о его невыносимом положение на работе [1]. 
Вместе с тем следует заметить, что количество споров по административным искам публичных служащих к администрации или высшего руководства соответствующего органа постоянно растет. При этом самую многочисленную группу составляют споры, возникающие в сфере дисциплинарного производства.

Как правило, нарушениями в сфере дисциплинарного производства административными судами выявлены следующие: 1) нарушение сроков привлечения служащего к дисциплинарной ответственности (Верховный Суд, 2019); 2) привлечение к дисциплинарной ответственности в период временной нетрудоспособности и без проведения предварительного служебного расследования (Верховный Суд, 2019); 3) привлечение к дисциплинарной ответственности без фактического доказательства факта совершения дисциплинарного проступка (отсутствие вины служащего) (Верховный Суд, 2019); 4) отсутствие должного мотивирования решения о применении определенных норм права или неприменении других норм, при выборе вида дисциплинарного взыскания, а также отсутствие приведения обстоятельств совершения дисциплинарного проступка (Верховный Суд, 2019) и др.

К делам данной группе следует отнести также дела по: обжалованию порядка и/или результатов проведения аттестации публичных служащих (Верховный Суд, 2018), перевода с одной должности на другую (внутреннее перемещение) (Верховный Суд, 2019), оплаты труда служащих (Верховный Суд, 2018) и др.

К примеру, в деле № 820/4210/16 работник органов Национальной полиции обратился с иском к Главному управлению Национальной полиции в Харьковской области, в котором просил признать противоправным и отменить решение аттестационной комиссии, оформленное протоколом, мотивируя свои исковые требования тем, что результаты аттестации являются необоснованными. В ходе рассмотрения дела суд первой инстанции, с которым в целом согласились суд апелляционной и кассационной инстанций, пришел к выводу о том, что ответчиком не представлено доказательств того, что при принятии решения о несоответствии занимаемой должности по совокупной оценки всех критериев истец представил себя как неквалифицированный работник, поскольку негативная оценка деловых, профессиональных, личных качеств полицейского, его образовательного и квалификационного уровней, предоставленные аттестационной комиссией, не согласуется с доказательствами о положительной оценке этого же полицейского [11].

То есть по данному делу административными судами выявлен факт несоответствия результатов аттестационной оценки с доказательствами относительно положительной оценки деятельности истца на соответствующей должности.

Еще одним примером является дело № 815/2998/18 по иску служащего органов Государственной фискальной службы к управлению, в котором он проходил службу, с просьбой признать противоправными действия управления 
о предоставлении преимущественного права при переводе на должность начальника другому лицу. В этом деле иск был оставлен без удовлетворения, поскольку выяснилось, что руководством были выполнены все требования КЗоТ Украины [20]. То есть в данном делу констатировано, что на споры, возникающие при высвобождении служащих, сокращение их численности или внесении других изменений в штатное расписание, гарантии, определенные трудовым законодательством, как правило, распространяются на соответствующих служащих.

Выводы. Административным судам подведомственны такие категории споров, возникающих по поводу принятия граждан на публичную службу и ее прохождения: 1) по жалобам на решения конкурсной комиссии, других субъектов, уполномоченных принимать решения в сфере конкурсного отбора, об отмене результатов конкурсного отбора, допущения/недопущения к участию в конкурсе; 2) обжалования порядка и/или осуществления дисциплинарного производства; 3) обжалование порядка и/или результатов проведения аттестации публичных служащих; 4) обжалование перевода с одной должности на другую (внутреннее перемещение); 5) по жалобам служащих по размеру оплаты труда; 6) обжалования правомерности освобождения публичного служащего от занимаемой должности.

Основными проблемными аспектами рассмотрения споров, возникающих по поводу принятия граждан на публичную службу, ее прохождения и увольнения, в административных судах является неопределенность или отсутствие однозначного практики по решению таких вопросов: 1) нормы какого законодательства имеют приоритетное значение при применении к спорным правоотношениям (трудового или о государственной службе); 2) на какие категории споров распространяется юрисдикция административных судов (например, четко не определено, распространяется ли юрисдикция административных судов на споры, возникающие в сфере прохождения патронатной службы, в сфере приема, увольнения и прохождения службы на должности руководителей государственных предприятий и учреждений и т.д.) 3) каковы пределы осуществления судебного контроля по делам этой категории; 4) порядок и размер возмещения морального или материального ущерба, причиненного работодателем в связи с неправомерным решением о переводе, увольнении, привлечении к дисциплинарной ответственности и тому подобное.

Для решения проблемных вопросов, возникающих при рассмотрении споров в сфере публичной службы в административных судах, необходимо: обновить обобщения судебной практики по спорам, возникающим в сфере принятия, прохождения и увольнения с публичной службы; обобщить судебную практику о возмещении морального и материального ущерба в этой категории дел; четко определить, на какие категории споров, возникающие в сфере принятия, прохождения и увольнения с публичной службы, распространяется юрисдикция административных судов. 


\section{Лumepamypa:}

1. Акулов-Муратов В. (2018) Щодо принципів функціонування адміністративного судочинства у сфері встановлення та підтримки стейкхолдерських відносин керівників та їх підлеглих на державній службі в Україні. Публічна служба і адміністративне судочинство: здобутки і виклики. ВД «Дакор».

2. Банчук О. (2018) Проблеми конкурсного відбору осіб на службу в Національну поліцію України в світлі практики адміністративних судів. ВД «Дакор».

3. Дишлева I. (2019) Права та обов'язки державних службовців. Підприємництво, господарство і право. № 6. С. 152-156.

4. Кодекс адміністративного судочинства України: Кодекс України від 06.07.2005 № 2747-IV. URL : https://zakon.rada.gov.ua/laws/show/2747-15.

5. Костюк В.Л. (2018) Концепція права на публічну службу у контексті сьогодення: науково-теоретичний аспект. Публічне право. № 2 (30). С. 18-27.

6. Постанова Великої Палати Верховного Суду (2019, № 804/8642/17), http://reyestr.court.gov.ua/Review/81171426 (12.12.2020).

7. Постанова Великої Палати Верховного Суду (2019, № П/9901/118/18). http://reyestr.court.gov.ua/Review/79988741 (12.12.2020).

8. Постанова Великої Палати Верховного Суду (2019, № П/9901/526/18). http://reyestr.court.gov.ua/Review/79413217 (12.12.2020).

9. Постанова Великої Палати Верховного http://reyestr.court.gov.ua/Review/85443478 (12.12.2020).

10. Постанова Великої Палати Верховного http://reyestr.court.gov.ua/Review/74409456 (12.12.2020).
11. Постанова
Верховного
Суду

$(2018$

Суду (2019, № 9901/14/19).

http://reestr.court.gov.ua/Review/72531891 (12.12.2020).

12. Постанова

Верховного

Суду

$(2019$

Суду (2018, № 800/492/17).

http://reyestr.court.gov.ua/Review/83576629 (12.12.2020).
13. Постанова
Верховного
Суду
$(2018$

1340/4847/18).

http://reyestr.court.gov.ua/Review/73397758 (12.12.2020).

14. Постанова Верховного Суду (2019, № $817 / 555 / 17)$.

http://www.reyestr.court.gov.ua/Review/79818289 (12.12.2020).

15. Постанова Верховного Суду (2019, № $819 / 843 / 17)$.

http://reyestr.court.gov.ua/Review/79846073 (12.12.2020).

16. Постанова Верховного Суду (2019, № 816/1566/16).

http://reyestr.court.gov.ua/Review/83647556 (12.12.2020).

17. Постанова Верховного Суду (2019, № 826/14177/17).

http://reyestr.court.gov.ua/Review/79266522 (12.12.2020).

18. Постанова Верховного Суду (2019, № 820/4038/18).

http://reyestr.court.gov.ua/Review/84405887 (12.12.2020).

19. Постанова Верховного Суду (2018, № 815/4701/16).

http://reyestr.court.gov.ua/Review/78771572 (12.12.2020).

20. Постанова Верховного Суду

http://reyestr.court.gov.ua/Review/85835993 (12.12.2020).

21. Постанова Верховного Суду (2019, № $826 / 16348 / 18)$.

http://www.reyestr.court.gov.ua/Review/85154808 (12.12.2020).

22. Постанова Верховного Суду (2019, № 826/6219/18).

http://www.reyestr.court.gov.ua/Review/80728555 (12.12.2020).

23. Постанова Верховного Суду (2018, № 826/15786/15).

http://reyestr.court.gov.ua/Review/74408423 (12.12.2020).

24. Про внесення змін до деяких законів України щодо перезавантаження влади: Закон України (2019). https://zakon.rada.gov.ua/laws/show/117-20\#n54 (12.12.2020). 
25. Про державну службу: Закон України (2015) https://zakon.rada.gov.ua/laws/show/889-19 (12.12.2020).

26. Цуркан М. І. (2010) Правове регулювання публічної служби в Україні. Особливості судового розгляду спорів: монографія.

\section{References}

1. Akulov-Muratov V. (2018) Shchodo pryntsypiv funktsionuvannia administratyvnoho sudochynstva u sferi vstanovlennia ta pidtrymky steikkholderskykh vidnosyn kerivnykiv ta yikh pidlehlykh na derzhavnii sluzhbi v Ukraini [On the principles of administrative justice in the field of establishing and maintaining stakeholder relations of managers and their subordinates in the civil service in Ukraine]. Publichna sluzhba $i$ administratyvne sudochynstvo: zdobutky $i$ vyklyky - Public service and administrative justice: achievements and challenges : Proceedings of the First International Scientific and Practical Conference. (pp. 6-8). Kyiv: VD «Dakor» [in Ukrainian].

2. Banchuk, O. (2018). Problemy konkursnoho vidboru osib na sluzhbu v Natsionalnu politsiiu Ukrainy $v$ svitli praktyky administratyvnykh sudiv [Problems of competitive selection of persons for service in the National Police of Ukraine in the light of the practice of administrative courts]. Kyiv: VD «Dakor» [in Ukrainian].

3. Dyshleva, I. (2019). Prava ta oboviazky derzhavnykh sluzhbovtsiv [Rights and responsibilities of civil servants]. Pidpryiemnytstvo, hospodarstvo i pravo - Entrepreneurship, economy and law, 6, 152-156 [in Ukrainian].

4. Kodeks Ukrainy "Kodeks administratyvnoho sudochynstva Ukrainy” : vid 06.07.2005,№ 2747-IV [Code of Ukraine "Code of Administrative Procedure of Ukraine” from 06.07.2005, № 2747-IV]. zakon.rada.gov.ua. Retrieved from https://zakon.rada.gov.ua/laws/show/2747-15 [in Ukrainian].

5. Kostiuk, V.L. (2018). Kontseptsiia prava na publichnu sluzhbu u konteksti sohodennia: naukovo-teoretychnyi aspekt [The concept of the right to public service in the context of today: scientific and theoretical aspect]. Publichne pravo - Public law, 2(30), 18-27 [in Ukrainian].

6. Postanova Velykoi Palaty Verkhovnoho Sudu № 804/8642/17 [Resolution of the Grand Chamber of the Supreme Court № 804/8642/17]. (2019). reyestr.court.gov.ua. Retrieved from http://reyestr.court.gov.ua/Review/81171426 [in Ukrainian].

7. Postanova Velykoi Palaty Verkhovnoho Sudu № П/9901/118/18 [Resolution of the Grand Chamber of the Supreme Court № П/9901/118/18]. (2019). reyestr.court.gov.ua. Retrieved from http://reyestr.court.gov.ua/Review/79988741 [in Ukrainian].

8. Postanova Velykoi Palaty Verkhovnoho Sudu № П/9901/526/18 [Resolution of the Grand Chamber of the Supreme Court № П/9901/526/18]. (2019). reyestr.court.gov.ua. Retrieved from http://reyestr.court.gov.ua/Review/79413217 [in Ukrainian].

9. Postanova Velykoi Palaty Verkhovnoho Sudu № 9901/14/19 [Resolution of the Grand Chamber of the Supreme Court № 9901/14/19]. (2019). reyestr.court.gov.ua. Retrieved from http:// reyestr.court.gov.ua/Review/85443478 [in Ukrainian].

10. Postanova Velykoi Palaty Verkhovnoho Sudu № 800/492/17 [Resolution of the Grand Chamber of the Supreme Court № 800/492/17]. (2018). reyestr.court.gov.ua. Retrieved from http:// reyestr.court.gov.ua/Review/74409456 [in Ukrainian].

11. Postanova Verkhovnoho Sudu № 820/4210/16 [Resolution of the Supreme Court № 820/4210/16]. (2018). reestr.court.gov.ua. Retrieved from http://reestr.court.gov.ua/Review/72531891 [in Ukrainian].

12. Postanova Verkhovnoho Sudu № 1340/4847/18 [Resolution of the Supreme Court №

1340/4847/18]. (2019). reyestr.court.gov.ua. Retrieved from http://reyestr.court.gov.ua/Review/83576629 [in Ukrainian]. 
13. Postanova Verkhovnoho Sudu № A/9901/96/18 [Resolution of the Supreme Court № A/9901/96/18]. (2018). reyestr.court.gov.ua. Retrieved from http://reyestr.court.gov.ua/Review/73397758 [in Ukrainian].

14. Postanova Verkhovnoho Sudu № 817/555/17 [Resolution of the Supreme Court № 817/555/17]. (2019). reyestr.court.gov.ua. Retrieved http://www.reyestr.court.gov.ua/Review/79818289 [in Ukrainian].

15. Postanova Verkhovnoho Sudu № 819/843/17 [Resolution of the Supreme Court № 819/843/17]. (2019). reyestr.court.gov.ua. Retrieved http://reyestr.court.gov.ua/Review/79846073 [in Ukrainian].

16. Postanova Verkhovnoho Sudu № 816/1566/16 [Resolution of the Supreme Court № 816/1566/16]. (2019). reyestr.court.gov.ua. Retrieved from http://reyestr.court.gov.ua/Review/83647556 [in Ukrainian].

17. Postanova Verkhovnoho Sudu № 826/14177/17 [Resolution of the Supreme Court № 826/14177/17]. (2019). reyestr.court.gov.ua. Retrieved from http://reyestr.court.gov.ua/Review/79266522 [in Ukrainian].

18. Postanova Verkhovnoho Sudu № 820/4038/18 [Resolution of the Supreme Court № 820/4038/18]. (2019). reyestr.court.gov.ua. Retrieved from http://reyestr.court.gov.ua/Review/84405887 [in Ukrainian].

19. Postanova Verkhovnoho Sudu № 815/4701/16 [Resolution of the Supreme Court № 815/4701/16]. (2018). reyestr.court.gov.ua. Retrieved from http://reyestr.court.gov.ua/Review/78771572 [in Ukrainian].

20. Postanova Verkhovnoho Sudu № 815/2998/18 [Resolution of the Supreme Court № 815/2998/18]. (2019). reyestr.court.gov.ua. Retrieved from http://reyestr.court.gov.ua/Review/85835993 [in Ukrainian].

21. Postanova Verkhovnoho Sudu № 826/16348/18 [Resolution of the Supreme Court № 826/16348/18]. (2019). reyestr.court.gov.ua. Retrieved from http://www.reyestr.court.gov.ua/Review/85154808 [in Ukrainian].

22. Postanova Verkhovnoho Sudu № 826/6219/18 [Resolution of the Supreme Court № 826/6219/18]. (2019). reyestr.court.gov.ua. Retrieved from http://www.reyestr.court.gov.ua/Review/80728555 [in Ukrainian].

23. Postanova Verkhovnoho Sudu № 826/15786/15 [Resolution of the Supreme Court № 826/15786/15]. (2018). reyestr.court.gov.ua. Retrieved from http://reyestr.court.gov.ua/Review/74408423 [in Ukrainian].

24. Zakon Ukrainy "Pro vnesennia zmin do deiakykh zakoniv Ukrainy shchodo perezavantazhennia vlady" : vid 19 veresnia 2019 roku № 117-IX [Law of Ukraine "On amendments to some laws of Ukraine on the reset of power" from September 19 2019, № 117-IX]. (2019). zakon.rada.gov.ua. Retrieved from https://zakon.rada.gov.ua/laws/show/117-20\#n54 [in Ukrainian].

25. Zakon Ukrainy "Pro derzhavnu sluzhbu" : vid 10 hrudnia 2015 roku № 889-VIII [Law of Ukraine "On Civil Service" from December 10 2015, № 889-VIII]. (2015). zakon.rada.gov.ua. Retrieved from https://zakon.rada.gov.ua/laws/show/889-19 [in Ukrainian].

26. Tsurkan, M. I. (2010). Pravove rehuliuvannia publichnoi sluzhby v Ukraini. Osoblyvosti sudovoho rozghliadu sporiv [Legal regulation of public service in Ukraine. Features of litigation]. Kharkiv: Pravo [in Ukrainian]. 